Original Research

\title{
Implications of knee crepitus to the overall clinical presentation of women with and without patellofemoral pain
}

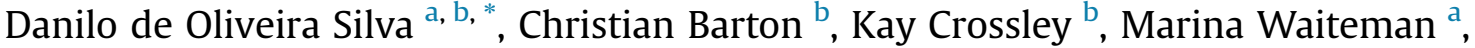 \\ Bianca Taborda ${ }^{a}$, Amanda Schenatto Ferreira ${ }^{a}$, Fábio Mícolis de Azevedo ${ }^{a}$ \\ a Laboratory of Biomechanics and Motor Control, School of Science and Technology, São Paulo State University (UNESP), Presidente Prudente, Brazil \\ ${ }^{\mathrm{b}}$ La Trobe Sports and Exercise Medicine Research Centre (LASEM), School of Allied Health, La Trobe University, Bundoora, Victoria, Australia
}

\section{A R T I C L E I N F O}

\section{Article history:}

Received 7 June 2018

Received in revised form

16 July 2018

Accepted 16 July 2018

\section{keywords:}

Knee pain

Kinesiophobia

Strength

Function

\begin{abstract}
A B S T R A C T
Objectives: Compare anthropometric characteristics, function, kinesiophobia, catastrophism and knee extensor strength between women (i) with PFP and crepitus (PFP crepitus); (ii) with PFP and no crepitus

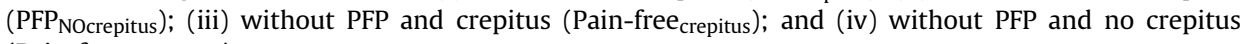
(Pain-free NOcrepitus). $_{\text {. }}$.

Design: Cross-sectional.

Setting: Laboratory study.

Participants: 65 women with PFP and 51 pain-free women.

Main outcome measures: Objective assessment of knee crepitus, forward step-down and single leg hop tests; knee extensor strength tests; and subjective ratings of function, kinesiophobia, pain catastrophising and knee stiffness.

Results: Crepitus was more common in women with PFP (50.7\%) compared to those without (33.3\%) $\left(\chi_{(1)}^{2}=4.17 ; \mathrm{p}=0.031\right)$. PFP $_{\text {crepitus }}$ and $\mathrm{PFP}_{\text {NOcrepitus }}$ groups had lower self-reported function; and higher kinesiophobia, catastrophism and knee stiffness compared to Pain-free crepitus $_{\text {and Pain-free }}$ NOcrepitus $_{\text {s. }}$ groups $(\mathrm{p}<0.001)$. PFP crepitus, PFP $_{\text {NOcrepitus }}$ and Pain-free ${ }_{\text {crepitus }}$ groups had lower functional performance

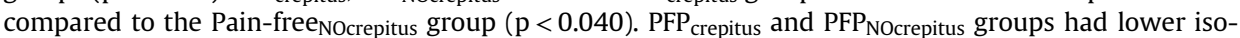
metric, concentric and eccentric knee extensor strength compared to the Pain-free NOcrepitus group $(\mathrm{p}<0.041)$, but not the pain-free ${ }_{\text {crepitus }}$ group. $\mathrm{PFP}_{\text {crepitus }}$ presented higher BMI than other groups $(\mathrm{p}=0.001)$.

Conclusion: Kinesiophobia, catastrophism, knee stiffness, strength and physical function are all impaired in women with PFP, regardless of crepitus. In pain-free women, crepitus was associated with poorer objective function.
\end{abstract}

(ㄱ) 2018 Elsevier Ltd. All rights reserved.

\section{Introduction}

Patellofemoral pain (PFP) affects up to $25 \%$ of active individuals (Glaviano, Kew, Hart, \& Saliba, 2015; Smith, Selfe, \& Rathleff, 2018b), and is thought to be linked with development of patellofemoral osteoarthritis (OA) later in life (Crossley, 2014; Wyndow, Collins, Vicenzino, Tucker, \& Crossley, 2016). Women are 2 times more likely to develop PFP than men (Boling et al., 2010). Clinically, people with PFP frequently report pain during activities that load

\footnotetext{
* Corresponding author. La Trobe University, Kingsbury Drive, Bundoora, VIC, 3086, Australia.

E-mail address: danilo110190@hotmail.com (D. de Oliveira Silva).
}

the patellofemoral joint in a flexed knee position (Crossley et al., 2016). Research indicates lower knee strength (Toumi et al., 2013), altered movement patterns (De Oliveira Silva, Barton, Pazzinatto, Briani, \& de Azevedo, 2016), kinesiophobia (Domenech, Sanchis-Alfonso, López, \& Espejo, 2013), increased body mass (Hart, Barton, Khan, Riel, \& Crossley, 2017) and knee crepitus (Crossley et al., 2016; De Oliveira Silva et al., 2018) are associated with PFP.

Knee crepitus is a frequent complaint for people with PFP, and its presence is reported as an inclusion criteria in some PFP studies (Kastelein et al., 2014; Nijs, Van Geel, Van Der Auwera, \& Van de Velde, 2006; Patil, White, Jones, \& Hui, 2010; Price, Jones, \& Allum, 2000). Crepitus without pain in the general population may be an important consideration. Specifically, in a population of 
people with no preexisting frequent knee symptoms and no radiographic osteoarthritis, knee crepitus has been reported to predict symptomatic knee OA (Lo et al., 2018) up to 4 years later, possibly representing early signs of patellofemoral OA (Schiphof et al., 2014). Despite being studied and reported in knee OA literature, the relative importance of knee crepitus is poorly understood in people with PFP.

For the individual with PFP, knee crepitus creates negative emotions and beliefs leading to altered behavior (e.g. kinesiophobia and reduced physical activity) (Robertson, Hurley, \& Jones, 2017). Despite this, recent reports indicate that knee crepitus is not associated with self-reported function and pain during several tasks in people with PFP (De Oliveira Silva et al., 2018). However, it is unknown if knee crepitus has an influence on other clinical features of PFP (e.g. pain catastrophism, kinesiophobia, lower physical function and strength), which might relate to poorer prognosis (Lankhorst et al., 2016). A better understanding of the relationship of crepitus with PFP and other associated clinical features could aid clinicians and research to determine the importance of developing and implementing treatment strategies to address the potential factors associated with it (Song, Park, Liang, \& Kim, 2018). Additionally, investigating the potential implication of knee crepitus on function and psychological profile in pain-free people could inform future longitudinal studies.

The aim of this study was to compare anthropometric characteristics, self-reported and objective function, knee stiffness, kinesiophobia, catastrophism and knee extensor strength between women (i) with PFP and crepitus ( PFP $_{\text {crepitus }}$ ); (ii) with PFP and no

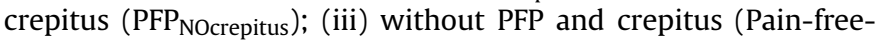

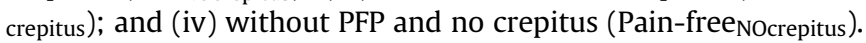

\section{Methods}

\subsection{Participants}

Sixty-five women with PFP and fifty-one pain-free women aged 18-35 years old were recruited via advertisements at universities and posts on social media (Facebook). In order to allow blinding of measurements, one physiotherapist that did not participate in the data collection was responsible for the recruitment. This crosssectional study was approved by the Local Ethics Committee. Each participant gave written informed consent prior to participation. Data from this paper are not a subsection of our recent study (Danilo De Oliveira Silva et al., 2018). The current data were collected in a subsequent data collection with a more comprehensive experimental design.

\subsection{Eligibility criteria}

The diagnosis of PFP was made by a physiotherapist (>six years of clinical experience) based on the eligibility criteria of previous studies (Crossley et al., 2016; Décary et al., 2018). The inclusion criteria were (1) reporting knee pain in at least two of the following activities: sitting for prolonged time, squatting, kneeling, running, jumping, landing, ascending or descending stairs; (2) insidious onset knee pain lasting at least 4 months; and (3) the worst pain level in the previous month corresponding to at least $30 \mathrm{~mm}$ in the 0-100 mm visual analogue pain scale (VAS). Participants needed to present all 3 criteria to be included in the PFP group. To be included in the pain-free group participants could not present any signs or symptoms of PFP or other musculoskeletal condition. Exclusion criteria, assessed by a physiotherapist, for both PFP and pain-free groups were as follows: (1) history of surgery in any lower limb joint, (2) history of patellar subluxation or clinical evidence of meniscal injury or ligament instability, or joint effusion, (3) symptomatic osteoarthritis in any lower limb joint assessed clinically according to OARSI criteria to diagnose patients with osteoarthritis, (4) symptomatic patellar tendon pathology, (5) referred pain coming from the lumbar spine, hips, ankles or feet, or (6) presence of medical conditions.

\subsection{Procedures}

A previously trained investigator explained to the participants in detail how to perform each test. Participant's symptomatic limb (unilateral symptoms) or most symptomatic limb (bilateral symptoms) was assessed (De Oliveira Silva et al., 2018). For the pain-free group, the dominant limb was evaluated (identified by asking which leg the participant would use to kick a ball as hard as possible). The investigator who performed all tests was blinded to condition (PFP or pain-free). Prior to data collection, demographic data including age, body mass and height were recorded. The data collection was separated in 2 days: Day one - Participants performed knee crepitus test, functional performance tests and completed the self-reported outcomes; Day 2 - Participants performed knee extensor strength tests.

\subsection{Knee crepitus clinical test}

The investigator placed the palm of the hand over the patella to detect the presence of a continuous grinding sensation during two squats as deep as the participants felt themselves comfortable, with maximum limit of $90^{\circ}$ of knee flexion (active knee flexion-extension movement) (Souza, 1997). The test was considered positive for knee crepitus when a grinding, crackling or crunching sensation during knee extension or flexion was detected (Song et al., 2018). However, just one or two clicks or pops were not considered as crepitus (Song et al., 2018). This test was previously reported to be reliable with Kappa value (95\% Confidence Interval) of 0.860 (0.727-0.993) for people with PFP and $0.906(0.816-0.995)$ for pain-free (De Oliveira Silva et al., 2018).

\subsection{Self-reported measures}

PFP participants and pain-free controls completed the Selfreported function (Anterior Knee Pain Scale - AKPS) (Crossley, Bennell, Cowan, \& Green, 2004; De Oliveira Silva et al., 2015), Kinesiophobia (Tampa Scale) (French, France, Vigneau, French, \& Evans, 2007; Kori, Miller, \& Todd, 1990), the Pain Catastrophizing Scale (PCS) (Sullivan, Bishop, \& Pivik, 1995) and a VAS (0-100 mm) for Knee Stiffness (how severe their knee stiffness usually is later in the day).

\subsection{Functional performance}

Two tasks were used to assess functional performance in women with PFP and pain-free controls: forward step-down test (FSDT) and single leg hop test (SLHT) (Fig. 1). Participants performed three familiarization trials before each test.

To perform the FSDT, participants stood on a $20 \mathrm{~cm}$ high platform in a bipedal stance and stepped forward to tap with their nontest leg on the ground in front of the step, while keeping the tested leg on the step, before returning to starting position, with their hands on the wrist during the entire test. The number of repetitions that the participant performed in $30 \mathrm{~s}$ was recorded by the investigator, and for the repetition to be validated, the participant should touch the floor only with the heel, returning the position of complete extension of the knee (Loudon, Wiesner, Goist-foley, Asjes, \& Loudon, 2002). 


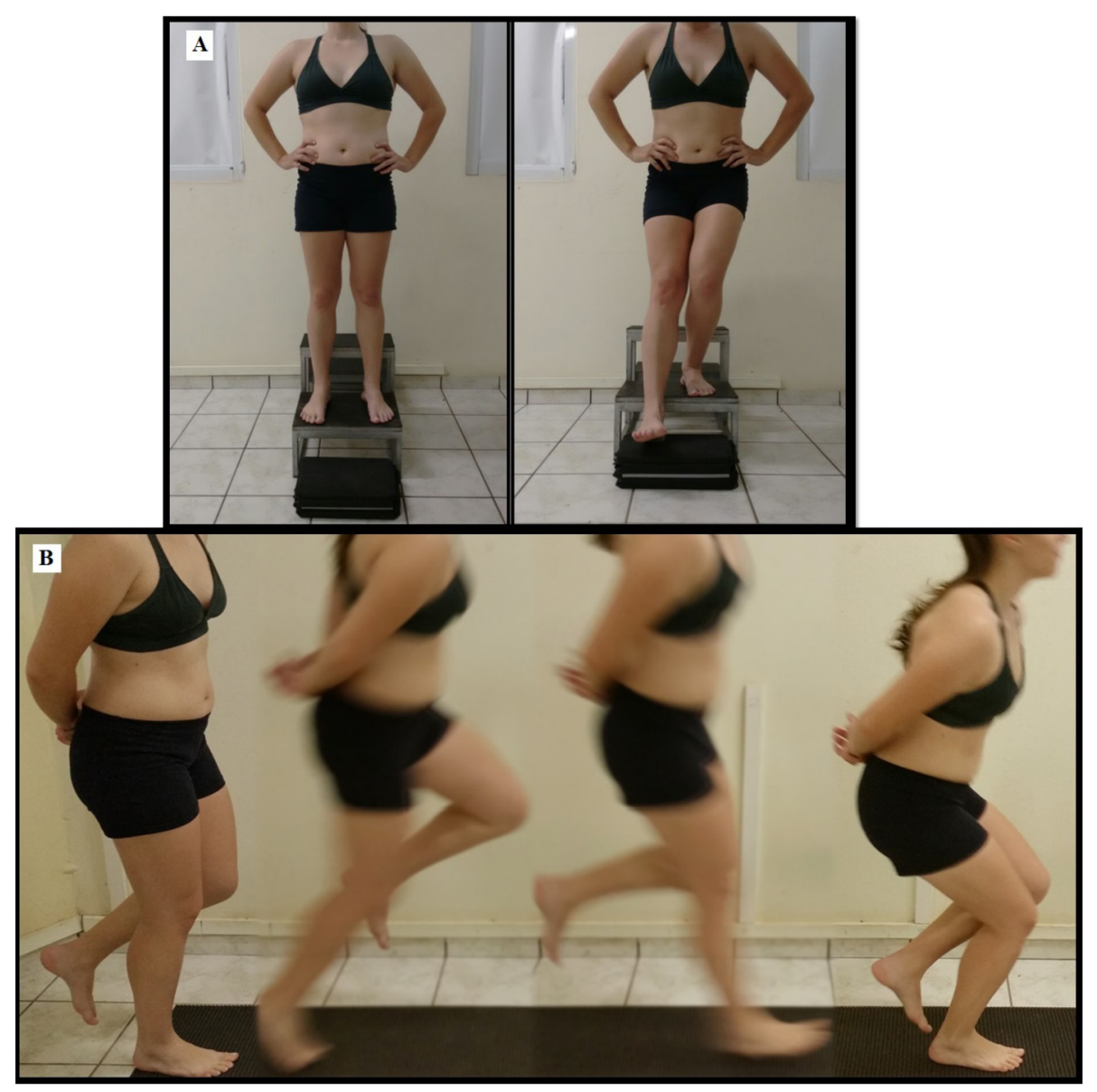

Fig. 1. Performance function tests. A) Forward step-down test. B) Single leg hop test.

To perform the SLHT, participants were positioned with the heel in a marked position on the floor and were instructed to stand in unipodal support with their arms crossed on their back. Then, the participants hopped forward with their test leg as far as possible landing on the same foot. The distance of the jump was measured in centimeters at the heel position from which the participant landed. In addition, the hop was validated only if the participant was able to maintain their balance upon landing, keeping their landing foot on the ground, without losing balance and moving the foot off the ground again, until the investigator marked where the participant landed. If the hop was not valid, participants were asked to repeat the task. The test was performed three times and the mean used for further analysis.

\subsection{Knee extensor strength tests}

We evaluated maximal voluntary isometric, concentric and eccentric, contractions during knee extension with an isokinetic dynamometer (Biodex System 4 Pro, New York, USA). Participants were assessed in the seated position with the hip and non-tested knee flexed to $90^{\circ}$. The center of the knee joint was aligned with the axis of the dynamometer and four belts were used to stabilize the trunk and limb under test, two crossing the trunk, one around the pelvis and one on the distal thigh. The knee extensor muscles were evaluated at a joint angle of $60^{\circ}$ (Nakagawa, Baldon, Muniz, \& Serrão, 2011; Pua, Clark, \& Bryant, 2010). The order of the contractions assessments was randomized.

Participants performed a familiarization procedure for the isometric test with 2 submaximal practice contractions of 6-s with an interval of 1-min between trials. Two maximal isometric contractions of 6-s with an interval of 1-min between each trial were performed to determine the maximum isometric strength. Participants also performed a familiarization for concentric and eccentric tests, consisting of one series of five submaximal contractions and one series of two maximal contractions, with a 1min interval between series (Baldon et al., 2011). Concentric and eccentric strength tests were performed at an angular velocity of $30^{\circ} / \mathrm{s}$ (Perin, 1993). In the sequence, they performed two series of five maximal repetitions with a 3-min rest period between the series. During all contractions a standardized verbal encouragement was provided to stimulate the participants to produce their maximum strength. To correct the influence of gravity, the assessed limb was weighed before each test and the isokinetic dynamometer software (Biodex System 4 Pro) automatically corrected the output data. Specifically, the participants had their assessed limbs positioned in $30^{\circ}$ of knee flexion from maximal knee extension. Then, participants were asked to let their limb relax into the isokinetic dynamometer arm, which performed the weight measurement.

The isokinetic data were analyzed using a custom code in MatLab (MATLAB; The MathWorks, Inc, Natick, MA). The variables of interest were peak isometric, concentric and eccentric knee extensor strength. The mean of the two maximum isometric contractions of each participant was used in the statistical analysis. For concentric and eccentric peak knee extensor strength we used the mean of the middle 3 repetitions for each strength test (Boling and Padua, 2009). All torque data (N.m) were normalized by body mass ([N.m/kg] x 100) (Baldon et al., 2011). 


\subsection{Statistical analysis}

Firstly, we divided the sample in four groups based on the presence of PFP and knee crepitus: PFP and no knee crepitus

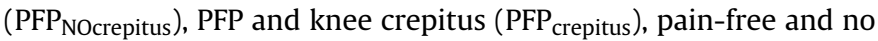

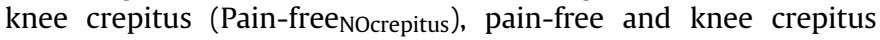

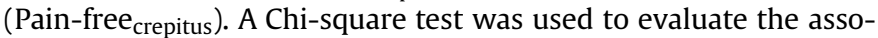
ciation between the presence of crepitus and the presence of PFP.

Mean age, height, body mass, body mass index, self-reported measures, performance-based function tests, isometric, concentric and eccentric knee extensor strength were compared betweengroups using a one-way between-groups analysis of variance (ANOVA). In case of significant F-values ( $\mathrm{p}<0.05)$, adjusted Tukey's post-hoc tests were calculated to identify which groups were different. The data reported from ANOVA are the F values (with degrees of freedom) and p-values. In order to do not draw conclusions based solely on p-values, we calculated the mean difference (95\% confidence intervals $[\mathrm{CI}]$ ) and effect sizes $(95 \% \mathrm{CI})$ (Cohen's d) for each post hoc comparison with $\mathrm{p}<0.05$. The guidelines for interpreting the Cohen's d are: 0 to 0.40 small effect, 0.41 to 0.70 moderate effect, 0.71 or higher large effect (Cohen, 1988, p. 2). Statistical analyses were performed using the Statistical Software for Social Sciences (IBM 23.0, SPSS inc., Chicago, IL) with an a priori level of significance of 0.05 .

\section{Results}

\subsection{Presence of knee crepitus}

Of the 65 women with PFP, 33 (50.7\%) with, and 32 (49.3\%) without knee crepitus were identified. Of the 51 pain-free women, 17 (33.3\%) with, and 36 (66.7\%) without knee crepitus were identified. Crepitus was found to be significantly associated with the presence of PFP $\left(\chi_{(1)}^{2}=4.17 ; \mathrm{p}=0.031\right)$. Demographics, selfreported outcome measures, functional performance and knee extensor strength tests for each group are presented in Table 1.

\subsection{Demographics and self-reported measures}

There were no significant differences between-groups for age $(\mathrm{p}=0.383)$ and height $(\mathrm{p}=0.584)$. However, the PFP $\mathrm{Prepitus}_{\text {group }}$ presented higher body mass $(\mathrm{p}<0.001$, moderate to large effect sizes) and BMI ( $\mathrm{p}=0.001$, moderate to large effect sizes) than all three other groups (Table 2).

Both groups with PFP had lower self-reported function $(\mathrm{p}<0.001$, large effect size); and higher kinesiophobia $(\mathrm{p}<0.001$, large effect size), pain catastrophism ( $p<0.001$, large effect size) and knee stiffness ( $\mathrm{p}<0.001$, large effect size) compared to both pain-free groups (Table 3). There were no differences between

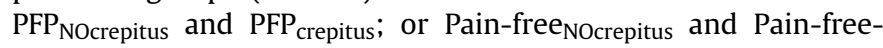
crepitus groups for any self-reported outcome measure.

\subsection{Functional performance and knee extensor strength}

Both groups with PFP, and the Pain-free crepitus $_{\text {group had lower }}$ functional performance during the FSDT ( $p<0.040$, moderate effect size) and SLHT ( $p<0.039$, small to moderate effect sizes)

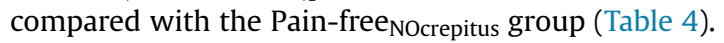

Both groups with PFP also had lower knee extensor strength in isometric, concentric and eccentric contractions ( $\mathrm{p}<0.041$, small to

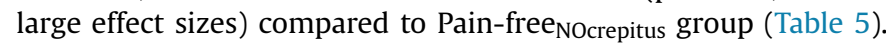
There were no differences between $\mathrm{PFP}_{\text {NOcrepitus }}$ and $\mathrm{PFP}_{\text {crepitus; }}$ or PFP groups and Pain-free crepitus $_{\text {group. }}$

\section{Discussion}

Our findings indicate that knee crepitus is significantly more prevalent in women with PFP (50.7\%) than in pain-free controls (33.3\%). Our findings also indicate higher kinesiophobia and pain catastrophism in women with PFP, in those with and without crepitus. Additionally, self-reported function was lower, and knee stiffness higher in the PFP group compared to pain-free controls, regardless of whether knee crepitus was present or not.

Table 2

Mean difference 95\% confidence intervals (CI's) and effect sizes of the post hoc comparisons with $\mathrm{p}<0.05$ for anthropometric measures.

\begin{tabular}{|c|c|c|}
\hline Variables & Mean difference (95\% CI) & Effect size $(95 \% \mathrm{CI})$ \\
\hline \multicolumn{3}{|l|}{ Body mass ( $k g)$} \\
\hline $\mathrm{PFP}_{\text {crepitus }}$ vs PFP $\mathrm{NOcrepitus}$ & $4.79(0.35-9.23)$ & $0.41(0.09-0.89)$ \\
\hline PFP $_{\text {crepitus vs Pain-free }}$ crepitus & $9.02(4.29-13.74)$ & $1.19(0.57-1.83)$ \\
\hline $\begin{array}{l}P_{\text {crepitus }} \text { vs Pain-free } \\
\text { BMI }\left(\mathrm{kg} / \mathrm{m}^{2}\right)\end{array}$ & $7.52(3.89-11.14)$ & $1.17(0.65-1.67)$ \\
\hline $\mathrm{PFP}_{\text {crepitus }}$ vs $\mathrm{PFP}_{\text {NOcrepitus }}$ & $1.97(0.20-3.73)$ & $0.55(0.55-1.04)$ \\
\hline PFP $_{\text {crepitus vs Pain-free }}$ crepitus & $3.12(1.31-4.93)$ & $1.10(0.60-1.62)$ \\
\hline $\mathrm{PFP}_{\text {crepitus }}$ vs Pain-free NOcrepitus & $2.72(1.21-4.24)$ & $0.88(0.23-1.45)$ \\
\hline
\end{tabular}

Table 1

Characteristics of the participants.

\begin{tabular}{|c|c|c|c|c|c|c|}
\hline Variables & Pain-free $_{\text {NOcrepitus }}$ & Pain-free ${ }_{\text {crepitus }}$ & PFP $_{\text {NOcrepitus }}$ & PFP $_{\text {crepitus }}$ & F-ratio & p-value \\
\hline \multicolumn{7}{|l|}{ Demographics } \\
\hline Age (years) & $22.06(2.81)$ & $22.18(3.57)$ & $21.53(3.87)$ & $22.91(2.56)$ & 1.02 & 0.383 \\
\hline Height (m) & $1.64(0.03)$ & $1.62(0.04)$ & $1.64(0.05)$ & $1.63(0.06)$ & 0.132 & 0.584 \\
\hline Body Mass (kg) & $57.82(5.65)$ & $56.92(6.92)$ & $61.94(7.55)$ & $64.72(6.12)$ & 7.89 & $<0.001$ \\
\hline BMI & $22.01(2.82)$ & $21.61(2.15)$ & $22.77(3.74)$ & $24.74(3.36)$ & 5.50 & 0.001 \\
\hline \multicolumn{7}{|l|}{ Self-reported measures } \\
\hline Function (AKPS) & $98.56(2.31)$ & 98.29 (3.09) & $70.94(10.58)$ & $74.82(9.25)$ & 107.92 & $<0.001$ \\
\hline Kinesiophobia & $28.32(4.74)$ & $28.47(4.41)$ & $36.28(6.77)$ & $36.30(6.84)$ & 16.82 & $<0.001$ \\
\hline Pain Catastrophism & $1.29(3.52)$ & $3.24(4.59)$ & $16.06(9.94)$ & $12.55(7.67)$ & 30.07 & $<0.001$ \\
\hline Knee Stiffness (VAS) & $0.79(2.50)$ & $4.71(9.40)$ & $27.88(2.68)$ & $28.36(1.25)$ & 19.90 & $<0.001$ \\
\hline \multicolumn{7}{|c|}{ Performance based function tests } \\
\hline FSDT (repetitions) & $21.26(5.92)$ & $18.24(6.00)$ & $17.53(4.79)$ & $17.91(6.44)$ & 2.86 & 0.040 \\
\hline SLHT $(\mathrm{cm})$ & $96.96(19.61)$ & $86.41(17.95)$ & $85.50(14.94)$ & $90.81(23.13)$ & 2.96 & 0.039 \\
\hline \multicolumn{7}{|l|}{ Knee extensor strength } \\
\hline Isometric (Peak TQ/BW) & $278.27(60.82)$ & $265.88(56.60)$ & $225.23(68.37)$ & $223.85(72.89)$ & 5.51 & 0.001 \\
\hline Concentric (Peak TQ/BW) & $223.40(41.71)$ & $215.34(41.71)$ & $205.85(71.52)$ & $183.51(63.62)$ & 2.84 & 0.041 \\
\hline Eccentric (Peak TQ/BW) & $279.55(70.52)$ & $265.33(80.08)$ & $237.66(70.21)$ & $230.75(81.01)$ & 2.98 & 0.034 \\
\hline
\end{tabular}

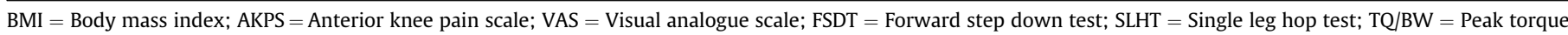
normalized by body weight. 
Table 3

Mean difference 95\% confidence intervals ( $\mathrm{Cl}$ 's) and effect sizes of the post hoc comparisons with $\mathrm{p}<0.05$ for self-reported measures.

\begin{tabular}{|c|c|c|}
\hline Variables & Mean difference $(95 \% \mathrm{CI})$ & Effect size $(95 \% \mathrm{CI})$ \\
\hline \multicolumn{3}{|l|}{ Anterior Knee Pain Scale (AKPS) } \\
\hline $\mathrm{PFP}_{\text {crepitus }}$ vs Pain-free crepitus & $-23.47(-28.13$ to -18.81$)$ & $3.40(2.67-4.18)$ \\
\hline $\mathrm{PFP}_{\text {crepitus }}$ vs Pain-free NOcrepitus & $-23.74(-27.00$ to -20.47$)$ & $3.52(2.19-3.90)$ \\
\hline PFP $_{\text {NOcrepitus }}$ vs Pain-free ${ }_{\text {crepitus }}$ & $-27.35(-32.66$ to -22.05$)$ & $3.50(2.78-4.34)$ \\
\hline $\begin{array}{l}\text { PFP }_{\text {NOcrepitus }} \text { vs Pain-free } \\
\text { KOcrepitus } \\
\text { Kinesiophobia }\end{array}$ & $-27.62(-31.33$ to -23.90$)$ & $3.60(2.25-4.00)$ \\
\hline 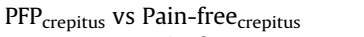 & $7.83(4.14-11.52)$ & $1.36(0.83-1.88)$ \\
\hline $\mathrm{PFP}_{\text {crepitus }}$ vs Pain-free ${ }_{\text {NOcrepitus }}$ & $7.98(5.11-10.84)$ & $1.35(0.62-1.90)$ \\
\hline PFP $_{\text {NOcrepitus }}$ vs Pain-free crepitus & $7.81(4.14-11.47)$ & $1.37(0.84-1.90)$ \\
\hline $\begin{array}{l}\text { PFP }_{\text {NOcrepitus vs Pain-free }} \text { NOcrepitus } \\
\text { Pain catastrophism }\end{array}$ & $7.95(5.09-10.81)$ & $1.27(0.63-1.92)$ \\
\hline PFP $_{\text {crepitus }}$ vs Pain-free crepitus & $9.31(5.22-13.39)$ & $1.47(0.94-2.01)$ \\
\hline PFP $_{\text {crepitus vs Pain-free }}$ Nocrepitus & $11.25(8.35-14.15)$ & $1.68(1.00-2.36)$ \\
\hline PFP $_{\text {NOcrepitus }}$ vs Pain-free crepitus & $12.82(7.69-17.96)$ & $1.67(1.11-2.23)$ \\
\hline $\begin{array}{l}\text { PFP }_{\text {NOcrepitus }} \text { vs Pain-free } \\
\text { Knece stiffness }(0-100 \text { mm VAS })\end{array}$ & $14.76(11.14-18.39)$ & $1.74(1.05-2.43)$ \\
\hline PFP $_{\text {crepitus }}$ vs Pain-free crepitus & $23.65(11.25-33.05)$ & $3.52(2.66-4.17)$ \\
\hline $\mathrm{PFP}_{\text {crepitus }}$ vs Pain-free NOcrepitus & $27.57(20.23-34.90)$ & $13.94(12.16-18.54)$ \\
\hline PFP $_{\text {NOcrepitus }}$ vs Pain-free crepitus & $23.16(10.11-36.22)$ & $3.35(2.50-3.97)$ \\
\hline PFP $_{\text {NOcrepitus }}$ vs Pain-free NOcrepitus & $27.08(19.26-34.89)$ & 10.45 (7.99-12.35) \\
\hline
\end{tabular}

Table 4

Mean difference 95\% confidence intervals (CI's) and effect sizes of the post hoc comparisons with p $<0.05$ for objective measures of function.

\begin{tabular}{|c|c|c|}
\hline Variables & Mean difference $(95 \% \mathrm{CI})$ & Effect size $(95 \% \mathrm{CI})$ \\
\hline \multicolumn{3}{|l|}{ Forward step-down test (repetitions) } \\
\hline PFP $_{\text {crepitus }}$ vs Pain-free ${ }_{\text {NOcrepitus }}$ & $-3.35(-6.37$ to -0.33$)$ & $0.54(0.07-1.12)$ \\
\hline $\mathrm{PFP}_{\text {NOcrepitus }}$ vs Pain-free ${ }_{\text {NOcrepitus }}$ & $-3.73(-6.39$ to -1.07$)$ & $0.69(0.10-1.31)$ \\
\hline Pain-free $_{\text {crepitus vs Pain-free }}$ NOcrepitus & $-3.02(-6.58$ to -0.52$)$ & $0.50(0.02-1.08)$ \\
\hline \multicolumn{3}{|l|}{ Single leg hop test $(\mathrm{cm})$} \\
\hline PFP $_{\text {crepitus vs Pain-free }}$ Nocrepitus & $-6.14(-16.59$ to -0.04$)$ & $0.28(-0.31$ to 0.86$)$ \\
\hline PFP $_{\text {NOcrepitus vs Pain-free }}$ NOcrepitus & $-11.46(-20.07$ to -2.84$)$ & $0.68(0.08-1.28)$ \\
\hline Pain-free $_{\text {crepitus }}$ vs Pain-free NOcrepitus & $-10.52(-21.92$ to -0.86$)$ & $0.56(0.04-1.16)$ \\
\hline
\end{tabular}

Table 5

Mean difference 95\% confidence intervals ( $\mathrm{Cl}$ 's) and effect sizes of the post hoc comparisons with $\mathrm{p}<0.05$ for knee extensor strength measures.

\begin{tabular}{|c|c|c|}
\hline Variables & Mean difference $(95 \% \mathrm{CI})$ & Effect size (95\% CI) \\
\hline \multicolumn{3}{|l|}{ Knee extensor isometric strength } \\
\hline PFP $_{\text {crepitus vs Pain-free }}$ NOcrepitus & $-54.41(-87.13$ to -21.70$)$ & $0.81(0.17-1.38)$ \\
\hline $\begin{array}{l}\text { PFP }_{\text {NOcrepitus vs Pain-free }} \text { Nocrepitus } \\
\text { Knee extensor concentric strength }\end{array}$ & $-53.04(-84.82$ to -21.26$)$ & $0.81(0.18-1.40)$ \\
\hline $\mathrm{PFP}_{\text {crepitus }}$ vs Pain-free NOcrepitus & $-39.88(-66.06$ to -13.71$)$ & $0.74(0.08-1.29)$ \\
\hline $\begin{array}{l}\text { PFP }_{\text {Nocrepitus vs Pain-free }} \text { NOcrepitus } \\
\text { Knee extensor eccentric strength }\end{array}$ & $-17.54(-46.13$ to -0.11$)$ & $0.29(-0.32$ to 0.87$)$ \\
\hline PFP $_{\text {crepitus }}$ Vs Pain-free NOcrepitus & $-48.79(-85.82$ to -11.76$)$ & $0.64(0.02-1.22)$ \\
\hline PFP $_{\text {NOcrepitus vs Pain-free }}$ NOcrepitus & $-41.88(-76.50$ to -7.25$)$ & $0.59(0.01-1.18)$ \\
\hline
\end{tabular}

Interestingly, women with PFP (with or without crepitus), and pain-free controls with crepitus had lower functional performance compared with pain-free controls with no crepitus. Additionally, both groups of women with PFP (with and without crepitus) had lower knee extensor strength compared to pain-free controls with no crepitus, but no difference compared with pain-free controls with crepitus.

Despite crepitus being more prevalent in women with PFP, one third of pain-free controls did present with crepitus. This rate is similar to a recent study with a larger cohort of women, which reported that $33.5 \%$ of pain-free women present knee crepitus (Danilo De Oliveira Silva et al., 2018). Additionally, in a populational study to investigate the prevalence of knee OA in people over 40 years old, crepitus was reported in $38.1 \%$ of women (Ho-Pham et al., 2014). Thus, clinically, the rate of knee crepitus in pain-free populations seems to range between 30 and $40 \%$.

Interestingly, our findings indicate that impaired functional performance (moderate effect) in pain-free women with knee crepitus compared to pain-free women without crepitus. It is possible that evaluating the presence or absence of knee crepitus may help identify those at higher risk of PFP development. However, a large number of women with PFP did not present crepitus, which highlights that the presence of crepitus is likely to only form part of a multifactorial injury risk screening process. In addition, knee extensor strength was different only between the PFP groups and pain free no crepitus group. This finding might indicate that further case-control studies assessing knee extensor strength should be cautious with the presence of knee crepitus in the painfree population as it is likely to impact their findings.

Knee crepitus can negatively affects patient's beliefs, and alters movement patterns in an attempt to avoid hearing the noise, and can be responsible for the lack of adherence to exercise therapy (Robertson et al., 2017). Interestingly, we found no difference in self-reported function, kinesiophobia, pain catastrophising, knee 
stiffness or strength between women with PFP and crepitus and women with PFP and no crepitus. This may mean that once symptoms have developed, the presence of crepitus may have minimal influence on common impairments reported in PFP. These findings add to recent reports that knee crepitus has no association with pain during squats and stair negotiation (De Oliveira Silva et al., 2018). This may be important to communicate to patients considering likely negative patients beliefs related to crepitus (Robertson et al., 2017).

Previous findings indicate that knee crepitus is common in painfree people, and poorly related with pain in people with PFP (De Oliveira Silva et al., 2018). However, patients are unsatisfied with the lack of explanation they receive from health professionals regarding its cause (Robertson et al., 2017). As patients with PFP have stressed their interest in understanding knee crepitus, we strongly recommend that clinicians be reasonable when informing patients about the meaning of crepitus and a differentiation between physiological and pathological crepitus should be made in order to avoid nocebic information. The source of crepitus remains unclear, but previous research indicates it could be due to gas bubbles in the synovial fluid, ligaments snapping, hypermobility or discoid meniscus (Song et al., 2018).

\subsection{Clinical implication}

Knee crepitus is poorly understood by patients and clinicians (Robertson et al., 2017; Song et al., 2018), many individuals become fearful of the noise related to crepitus and change their daily habits (Robertson et al., 2017; Song et al., 2018). In addition, individuals with PFP report they wish to understand more about their condition (Smith et al., 2018a), but often they do not have good experience with general practitioners or physiotherapists about the cause of PFP signs and symptoms such as knee crepitus (Robertson et al., 2017). Thus, clinicians may clarify to patients with PFP that knee crepitus may not influence their strength or physical function and is also common in people without pain (30-40\%). This information should be provided along with other education that crepitus is not related with self-reported pain in people with PFP (Danilo De Oliveira Silva et al., 2018) and should integrate current PFP evidence-based management (Collins et al., 2018; Lack, Neal, De Oliveira Silva, \& Barton, 2018). Additionally, the association of physical inactivity (Glaviano, Baellow, \& Saliba, 2017) with greater risk of developing, and progression of knee OA (Messier et al., 2013) should also be discussed with patients so that they understand the potential importance of remaining physically active and participating in exercise therapy despite knee crepitus.

\subsection{Limitations and future directions}

Although pain-free women with knee crepitus had impaired functional performance, the long-term implications of crepitus in a young pain-free population remains unclear. Further research is encouraged to investigate if knee crepitus triggers quadriceps muscle inhibition or if the lower function might be related to an activity avoidance behavior due to crepitus. In addition, understanding if crepitus is a risk factor for PFP development linked with impaired functional performance could allow early intervention in this population.

Due to the cross-sectional nature of this study, the longer-term influence of crepitus in women with PFP on prognosis including pain, kinesiophobia, catastrophism, and further declines in strength and functional performance is unknown. Further research in this area is encouraged. We did not look at the relationship of crepitus with imaging or joint health in this study. Considering links of crepitus with PFJ joint lesions in people with PFJ OA (Schiphof et al.,
2014), and knee OA development (Lo et al., 2018), we also encourage research to explore the influence of crepitus on joint health in PFP cross-sectionally and longitudinally. Additionally, psychometric properties of participants knee stiffness using a VAS were not tested in a population with PFP, we encourage further studies to validate this outcome. Despite investigating if kinesiophobia and pain catastrophism are different in the presence of knee crepitus, a more comprehensive screening of the psychological features (coping skills, fear-avoidance beliefs, self-efficacy, etc.) of women with PFP and its relationship with crepitus is warranted. Another limitation of our study was that five participants with PFP had a dominant limb different from the pain-free participants, this difference may have influenced our findings.

\section{Conclusion}

Women with PFP were more likely to have crepitus than painfree women. Women with PFP had higher kinesiophobia, catastrophism and knee stiffness compared to pain-free controls, regardless of the presence or absence of knee crepitus. In addition, women with PFP and pain-free controls with knee crepitus had lower functional performance compared to pain-free controls with no knee crepitus, indicating both pain and crepitus may detrimentally influence function.

\section{Declaration of interest}

None.

\section{Conflicts of interest}

None declared.

\section{Funding}

This research did not receive any specific grant from funding agencies in the public, commercial, or not-for-profit sectors.

\section{Ethical approval}

The study was approved by the São Paulo State University Ethics Committee (number: 1.484.129).

\section{Acknowledgments}

São Paulo Research Foundation (FAPESP) for a scholarship, author: DOS (2015/11534-1).

\section{References}

Baldon, R. D. M., Lobato, D. F. M., Carvalho, L. P., Santiago, P. R. P., Benze, B. G., \& Serrão, F. V. (2011). Relationship between eccentric hip torque and lower-limb kinematics: Gender differences. Journal of Applied Biomechanics, 27(3), 223-232. https://doi.org/10.1123/jab.27.3.223.

Boling, M. C., Padua, D. a, \& Alexander Creighton, R. (2009). Concentric and eccentric torque of the hip musculature in individuals with and without patellofemoral pain. Journal of Athletic Training, 44(1), 7-13. https://doi.org/10.4085/10626050-44.1.7.

Boling, M., Padua, D., Marshall, S., Guskiewicz, K., Pyne, S., \& Beutler, A. (2010) Gender differences in the incidence and prevalence of patellofemoral pain syndrome. Scandinavian Journal of Medicine \& Science in Sports, 20(5), 725-730. https://doi.org/10.1111/j.1600-0838.2009.00996.x.Gender.

Cohen, J. (1988). Statistical power analysis for the behavioral sciences. New York: Routledge.

Collins, N. J., Barton, C. J., Van Middelkoop, M., Callaghan, M. J., Rathleff, M. S., Vicenzino, B. T., et al. (2018). 2018 consensus statement on exercise therapy and physical interventions (orthoses, taping and manual therapy) to treat patellofemoral pain: Recommendations from the 5th international patellofemoral pain research retreat, gold coast, Australia, 2017. British Journal of Sports Medicine. 
https://doi.org/10.1136/bjsports-2018-099397, 20 June 2018

Crossley, K. M. (2014). Is patellofemoral osteoarthritis a common sequela of patellofemoral pain? British Journal of Sports Medicine, 48(6), 409-410. https://doi. org/10.1136/bjsports-2014-093445.

Crossley, K. M., Bennell, K. L., Cowan, S. M., \& Green, S. (2004). Analysis of outcome measures for persons with patellofemoral pain: Which are reliable and valid? Archives of Physical Medicine and Rehabilitation, 85(5), 815-822. https://doi.org/ 10.1016/S0003-9993(03)00613-0.

Crossley, K. M., Stefanik, J. J., Selfe, J., Collins, N. J., Davis, I. S., Powers, C. M., et al. (2016). 2016 Patellofemoral pain consensus statement from the 4th International Patellofemoral Pain Research Retreat, Manchester. Part 1: Terminology, definitions, clinical examination, natural history, patellofemoral osteoarthritis and patient-reported outcome m. British Journal of Sports Medicine, 50(14), 839-843. https://doi.org/10.1136/bjsports-2016-096384.

De Oliveira Silva, D., Barton, C. J., Pazzinatto, M. F., Briani, R. V., \& de Azevedo, F. M (2016). Proximal mechanics during stair ascent are more discriminate of females with patellofemoral pain than distal mechanics. Clinical Biomechanics, 35(5), 56-61. https://doi.org/10.1016/j.clinbiomech.2016.04.009.

De Oliveira Silva, D., Briani, R., Pazzinatto, M., Ferrari, D., Aragão, F., \& Azevedo, F. (2015). Vertical ground reaction forces are associated with pain and selfreported functional status in recreational athletes with patellofemoral pain. Journal of Applied Biomechanics, 31(6), 409-414. https://doi.org/10.1123/jab. 2015-0048.

De Oliveira Silva, D., Pazzinatto, M. F., Del Priore, L. B., Ferreira, A. S., Briani, R. V., Ferrari, D., et al. (2018). Knee crepitus is prevalent in women with patellofemoral pain, but is not related with function. Physical Activity and Pain. Physical Therapy in Sport, 33, 7-11. https://doi.org/10.1016/j.ptsp.2018.06.002.

Décary, S., Frémont, P., Pelletier, B., Fallaha, M., Sylvain, B., Martel-Pelletier, J., et al. (April 2018). Validity of combining history elements and physical examination tests to diagnose patellofemoral pain. Archives of Physical Medicine and Rehabilitation, 99(4), 607-614. https://doi.org/10.1016/j.apmr.2017.10.014.

Domenech, J., Sanchis-Alfonso, V., López, L., \& Espejo, B. (2013). Influence of kinesiophobia and catastrophizing on pain and disability in anterior knee pain patients. Knee Surgery, Sports Traumatology, Arthroscopy, 21(7), 1562-1568. https://doi.org/10.1007/s00167-012-2238-5.

French, D. J., France, C. R., Vigneau, F., French, J. A., \& Evans, R. T. (2007). Fear of movement/(re)injury in chronic pain: A psychometric assessment of the original English version of the tampa scale for kinesiophobia (TSK). Pain, 127(1-2), 42-51. https://doi.org/10.1016/j.pain.2006.07.016.

Glaviano, N. R., Baellow, A., \& Saliba, S. (2017). Physical activity levels in individuals with and without patellofemoral pain. Physical Therapy in Sport, 27, 12-16. https://doi.org/10.1016/j.ptsp.2017.07.002.

Glaviano, N. R., Kew, M., Hart, J. M., \& Saliba, S. (2015). Demographic and epidemiological trends in patellofemoral pain. International Journal of Sports Physical Therapy, 10(3), 281-290. https://doi.org/10.1590/bjpt-rbf.2014.0123.

Hart, H. F., Barton, C. J., Khan, K. M., Riel, H., \& Crossley, K. M. (2017). Is body mass index associated with patellofemoral pain and patellofemoral osteoarthritis? A systematic review and meta-regression and analysis. British Journal of Sports Medicine, 51(10), 781-790. https://doi.org/10.1136/bjsports-2016-096768.

Ho-Pham, L. T., Lai, T. Q., Mai, L. D., Doan, M. C., Pham, H. N., \& Nguyen, T. V. (2014) Prevalence of radiographic osteoarthritis of the knee and its relationship to selfreported pain. PLoS One, 9(4), 1-7. https://doi.org/10.1371/journal.pone. 0094563

Kastelein, M., Luijsterburg, P. A. J., Heintjes, E. M., van Middelkoop, M. Verhaar, J. A. N., Koes, B. W., et al. (2014). The 6-year trajectory of non-traumatic knee symptoms (including patellofemoral pain) in adolescents and young adults in general practice: A study of clinical predictors. British Journal of Sports Medicine, 49, 400-405. https://doi.org/10.1136/bjsports-2014-093557.

Kori, S. H., Miller, R. P., \& Todd, D. D. (1990). Kinesiophobia: A new view of chronic pain behavior. Pain Management, 3, 35-43.

Lack, S., Neal, B., De Oliveira Silva, D., \& Barton, C. (2018). How to manage patellofemoral pain - understanding the multifactorial nature and treatment options. Physical Therapy in Sport, 32, 155-166. https://doi.org/10.1016/j.ptsp.2018. 04.010

Lankhorst, N. E., van Middelkoop, M., Crossley, K. M., Bierma-Zeinstra, S. M. A.,
Oei, E. H. G., Vicenzino, B., et al. (2016). Factors that predict a poor outcome 5-8 years after the diagnosis of patellofemoral pain: A multicentre observational analysis. British Journal of Sports Medicine, 50(14), 881-886. https://doi.org/10. 1136/bjsports-2015-094664.

Lo, G. H., Strayhorn, M. T., Driban, J. B., Price, L. L., Eaton, C. B., \& Mcalindon, T. E. (2018). Subjective crepitus as a risk factor for incident symptomatic knee Osteoarthritis: Data from the osteoarthritis initiative. Arthritis Care \& Research, 70(1), 53-60. https://doi.org/10.1002/acr.23246.

Loudon, J. K. Wiesner, D, Goist-foley, H. L, Asjes, C, \& Loudon, K. L (2002) Intrarater reliability of functional performance tests for subjects with patellofemoral pain syndrome. Journal of Athletic Training, 37(3), 256-261.

Messier, S. P., Mihalko, S. L., Legault, C., Miller, G. D., Nicklas, B. J., Devita, P., et al. (2013). Effects of intensive diet and exercise on knee joint loads, inflammation, and clinical outcomes among overweight and obese adults with knee osteoarthritis: The IDEA randomized clinical trial. Journal of the American Medical Association, 310(12), 1263-1273. https://doi.org/10.1001/jama.2013.277669. Effects.

Nakagawa, T. H., Baldon, R. D. M., Muniz, T. B., \& Serrão, F. V. (2011). Relationship among eccentric hip and knee torques, symptom severity and functional capacity in females with patellofemoral pain syndrome. Physical Therapy in Sport, 12(3), 133-139. https://doi.org/10.1016/j.ptsp.2011.04.004.

Nijs, J., Van Geel, C., Van Der Auwera, C., \& Van de Velde, B. (2006). Diagnostic value of five clinical tests in patellofemoral pain syndrome. Manual Therapy, 11(1), 69-77. https://doi.org/10.1016/j.math.2005.04.002.

Patil, S., White, L., Jones, A., \& Hui, A. C. W. (2010). Idiopathic anterior knee pain in the young. A prospective controlled trial. Acta Orthopaedica Belgica, 76(3), 356-359. Retrieved from http://www.ncbi.nlm.nih.gov/pubmed/20698457.

Perin, D. H. (1993). Isokinetic exercise and assessment. Champaign, IL: Human Kinetics.

Price, a J., Jones, J., \& Allum, R. (2000). Chronic traumatic anterior knee pain. Injury, 31(5), 373-378. Retrieved from http://www.ncbi.nlm.nih.gov/pubmed/ 10775695.

Pua, Y. H., Clark, R. A., \& Bryant, A. L. (2010). Physical function in hip osteoarthritis: Relationship to isometric knee extensor steadiness. Archives of Physical Medicine and Rehabilitation, 91(7), 1110-1116. https://doi.org/10.1016/j.apmr.2010.04.001.

Robertson, C. J., Hurley, M., \& Jones, F. (2017). People's beliefs about the meaning of crepitus in patellofemoral pain and the impact of these beliefs on their behaviour: A qualitative study. Musculoskeletal Science and Practice, 28, 59-64. https://doi.org/10.1016/j.msksp.2017.01.012.

Schiphof, D., Van Middelkoop, M., De Klerk, B. M., Oei, E. H. G., Hofman, a., Koes, B. W., et al. (2014). Crepitus is a first indication of patellofemoral osteoarthritis (and not of tibiofemoral osteoarthritis). Osteoarthritis and Cartilage, 22(5), 631-638. https://doi.org/10.1016/j.joca.2014.02.008.

Smith, B. E., Moffatt, F., Hendrick, P., Bateman, M., Rathleff, M. S., Selfe, J., et al (2018a). The experience of living with patellofemoral pain - loss, confusion and fear-avoidance: A UK qualitative study. BMJ Open, 8(1). e018624 https://doi.org/ 10.1136/bmjopen-2017-018624.

Smith, B. E., Selfe, J., \& Rathleff, M. S. (2018b). Incidence and prevalence of patellofemoral pain: A systematic review and meta-analysis. PLoS One, 13(1). https:// doi.org/10.1371/journal.pone.0190892.

Song, S. J., Park, C. H., Liang, H., \& Kim, S. J. (2018). Noise around the knee. Clinical Orthopaedic Surgery, 10(1), 1-8. https://doi.org/10.4055/cios.2018.10.1.1.

Souza, T. A. (1997). In T. E. Hyde, \& M. S. Gengenbach (Eds.), Conservative management of sport injuries. Maryland: Williams \& Wilkins.

Sullivan, M. J. L., Bishop, S. R., \& Pivik, J. (1995). The pain catastrophizing Scale: Development and validation. Psychological Assessment, 7(4), 524-532. https:// doi.org/10.1037/1040-3590.7.4.524.

Toumi, H., Best, T. M., Pinti, A., Lavet, C., Benhamou, C. L., \& Lespessailles, E. (2013). The role of muscle strength \& activation patterns in patellofemoral pain. Clinical Biomechanics, 28(5), 544-548. https://doi.org/10.1016/j.clinbiomech.2013.04. 005.

Wyndow, N., Collins, N., Vicenzino, B., Tucker, K., \& Crossley, K. (2016). Is there a biomechanical link between patellofemoral pain and osteoarthritis? A narrative review. Sports Medicine, 46(12), 1797-1808. https://doi.org/10.1007/s40279016-0545-6. 